\title{
Converting a Conventional Vehicle into an Electric Vehicle (EV)
}

\author{
Jardel Eugenio da Silva ${ }^{1^{*}}$ \\ https://orcid.org/0000-0002-0037-3208 \\ Jair Urbanetz Junior ${ }^{1^{*}}$ \\ https://orcid.org/0000-0001-9355-1730
}

1 Universidade Tecnológica Federal do Paraná, PPGSE, Curitiba, Paraná, Brazil;

Received: 2018.11.05; Accepted: 2019.07.26.

*Correspondence: jardel.eugenio@hotmail.com; (J.E.S.); urbanetz@utfpr.edu.br; (J.U.J)

\section{HIGHLIGHTS}

- Converting a Conventional Vehicle into an Electric Vehicle (EV).

- Traditional topology of an EV.

- Construction of control and measurement panels

- Exterior of the Eco Auto.

\begin{abstract}
The electric vehicle (EV) is not a recent invention. Between the end of the XIX century and the beginning of the XX century, most motor vehicles were electric, due to their superior reliability and cleanliness, compared to that of vehicles driven by internal combustion engines (ICE). However, with the development of ICEs and the reduction of their price, electric cars were forgotten. Only almost a century later, they returned in the market due to a significant increase in fossil fuels prices, as well as to a growing environmental concern. EVs present a number of advantages over ICE vehicles: they are simpler and require less use and replacement of parts, resulting in lower maintenance costs; moreover, they do not release pollutants into the environment. However, their production cost is still much higher than that of ICE vehicles. In order to verify the possibility of converting a conventional vehicle into an electric one at a reasonable cost, achieving a good performance and a good $\mathrm{kWh} / \mathrm{km}$ ratio, an ICEpowered Mercedes-Benz Class A 190 was converted into an EV. The results of several tests indicate that the conversion is feasible, as the car reached an average travelling cost of $0.16 \mathrm{R} \$ / \mathrm{km}$, assuming a price for the energy of $0.63 \mathrm{R} \$ / \mathrm{kWh}$. Moreover, this cost could be as low as zero if solar radiation is utilized to generate electricity through photovoltaic panels, which is an even more environmentally sustainable solution..
\end{abstract}

Keywords: Electric vehicles; Photovoltaic panels; environment 


\section{INTRODUCTION}

Electric vehicle (EV) is not a recent invention. Between the end of the XIX century and the beginning of the $X X$ century, most of the vehicles were powered by electricity[1]. This was due to their reliability and cleanliness compared to that of vehicles powered by internal combustion engines (ICE). However, with the development of ICEs and the reduction of their price, electric cars have been forgotten for almost a century. Nowadays, with a significant increase in the price of fossil fuels, and a growing concern for the environment developed, the interest around EVs has grown again. The ICE is the main component responsible for the motion of a conventional automobile, whereas the fuel tank is of secondary importance. On the contrary, in EVs, the main components are the batteries (or energy accumulators), the controller and the electric motor [1].Several topologies and different architectures exist, which cover different applications of pure EVs. Because of the large number of topologies encountered during an initial literature research, only a set of components of different topologies was considered. These topologies were evaluated using widely available data of efficiency, weight, and applied power. On this basis, the best topology for the conversion of an conventional vehicleinto an EV was identified, and applied to a Mercedes Benz Class A 190, also termed "Eco Auto" thereafter.

\section{MATERIAL AND METHODS}

After the acquisition of the Mercedes Benz Class A 190, the main components required for the conversion were defined (Table 1). Figure 1 shows the Mercedes Benz Class A 190 after removing the ICE and their peripherals.

Table 1. Components of the adopted conversion topology

\begin{tabular}{|c|c|c|c|}
\hline Components & $\begin{array}{l}\text { Nominal } \\
\text { efficiency }\end{array}$ & Weight & Symbol \\
\hline Brushless 10kW Engine (BLDC) & 0.93 & $17 \mathrm{~kg}$ & \\
\hline $\begin{array}{c}\text { FOC (Field-Oriented Control) } \\
\text { Controller } 10 \mathrm{~kW}\end{array}$ & 0.99 & $2.5 \mathrm{~kg}$ & \\
\hline $\begin{array}{c}10.8 \text { kWh Battery (108 kW Peak } \\
\text { Power) }\end{array}$ & $\begin{array}{c}0.88 \text { (charge) } \\
0.94 \text { (discharge) }\end{array}$ & $324 \mathrm{~kg}$ & \\
\hline Variable ratio transmission & 0.97 & ------ & 王 \\
\hline
\end{tabular}

Source: Elaborated by the authors, based on reference [3]. 


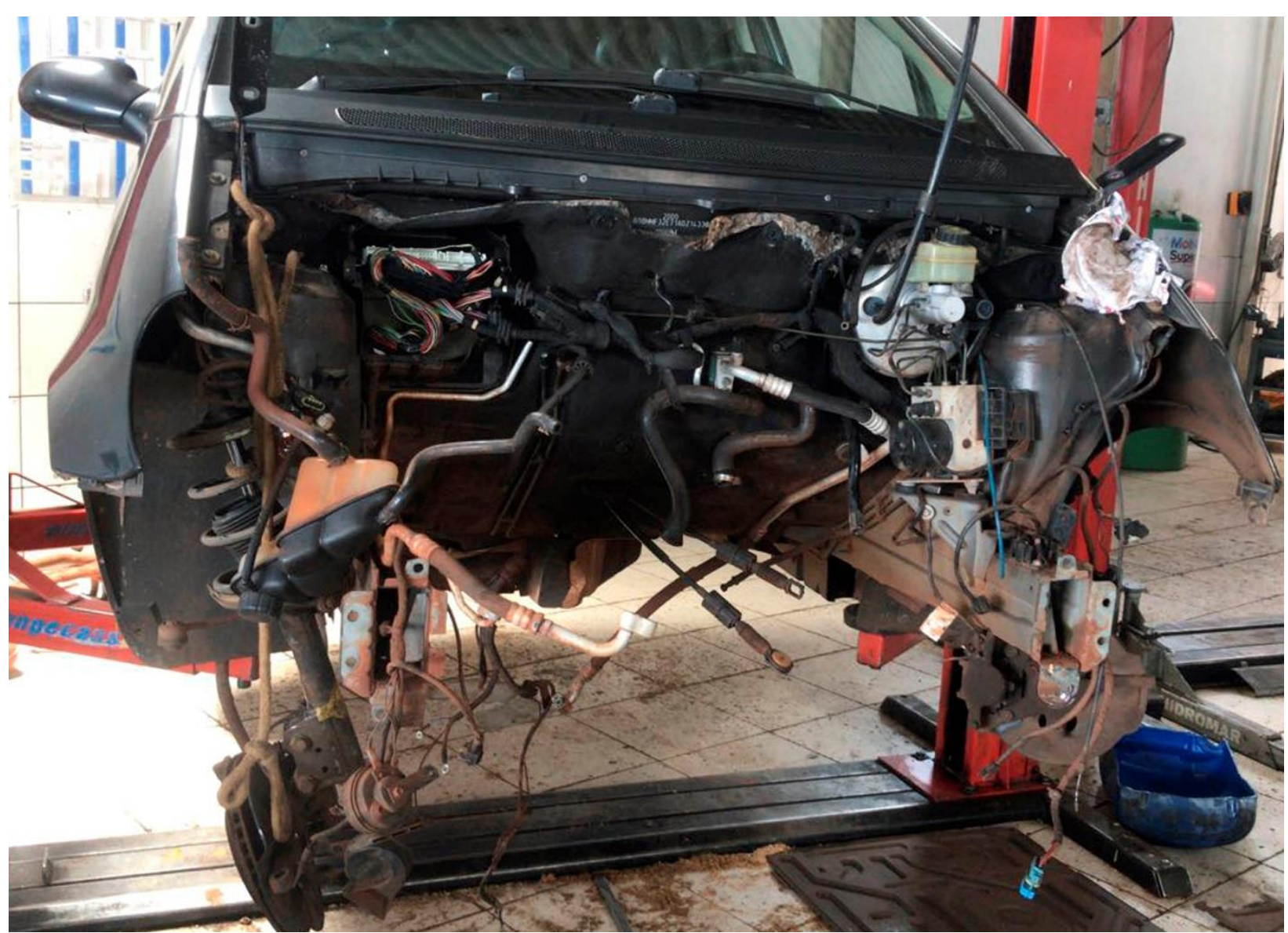

Figure 1. Removal of the Internal Combustion Engine (ICE).

\section{Topology}

The adopted topology is shown in Figure 2, and consists of a battery bank connected to a controller, which controls a brushless direct-current (BLDC) engine. When the driver accelerates, the withdrawal of energy from the source (battery) is increased, and this energy is delivered to the engine, increasing its rotation [2].

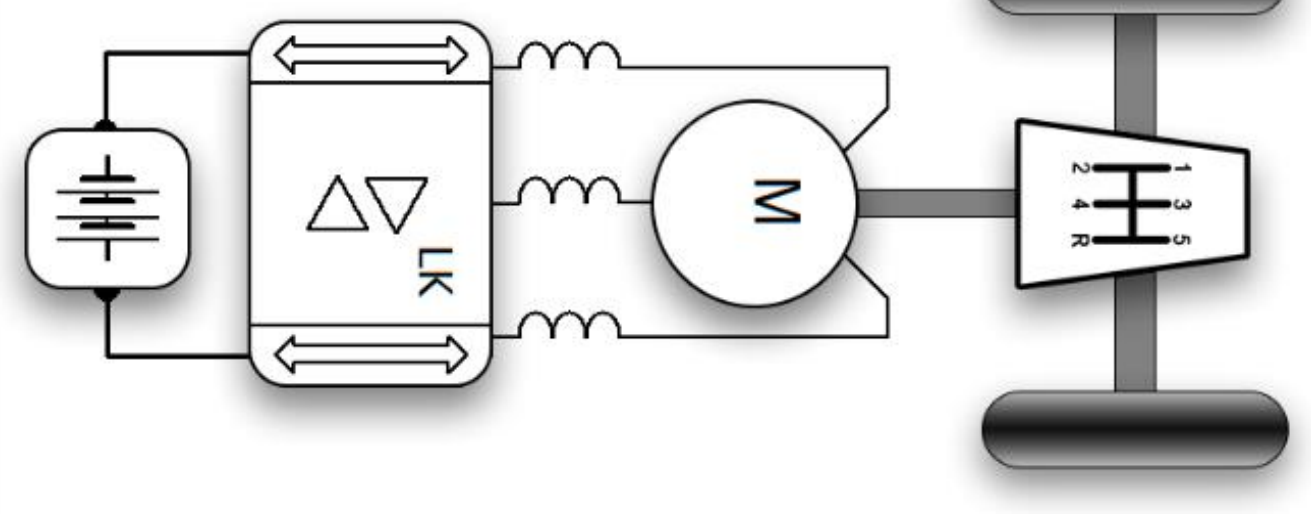

Figure 2. Traditional topology of an EV.

Elaborated by the authors, based on reference [3]

It is important to highlight that the electric engine produces the maximum torque at the start, and its efficiency curve remains almost constant until reaching high rotation rate. On the contrary, ICEs have a relatively low efficiency (between $5 \%$ and $10 \%$ ) at low rotation rates, which increases $(28 \%)$ at high rotation rates; overall, the mean efficiency 
is around $15 \%$. It is important to consider that, in urban areas, automobiles rarely work at high rotation rates, and that even when the vehicle is not moving, the combustion engine remains in operation, wasting energy [4].

\section{Engine}

The direct current (DC) engine is the most efficient for speed control without losing torque, with some disadvantages such as brush maintenance, size and weight. Therefore, we opted for a BLDC engine, despite its slightly higher cost and the need for a Field-Oriented Control (FOC) electronic control system. These engines offer some important advantages compared to conventional brush motors, such as a higher efficiency, minimum wear, longer life expectancy, compact design, higher energy density, less noise, and greater reliability. The conversion of the Class A entailed the use of a Brushless engine, similar to the model in Figure 3, with customizable resources, $72 \mathrm{~V}, 10 \mathrm{~kW}$, weighting $17 \mathrm{~kg}$, with a height of $170 \mathrm{~mm}$, a diameter of $206 \mathrm{~mm}$, and a 2000-6000 rpm (customizable) speed, with 93.5\% efficiency.

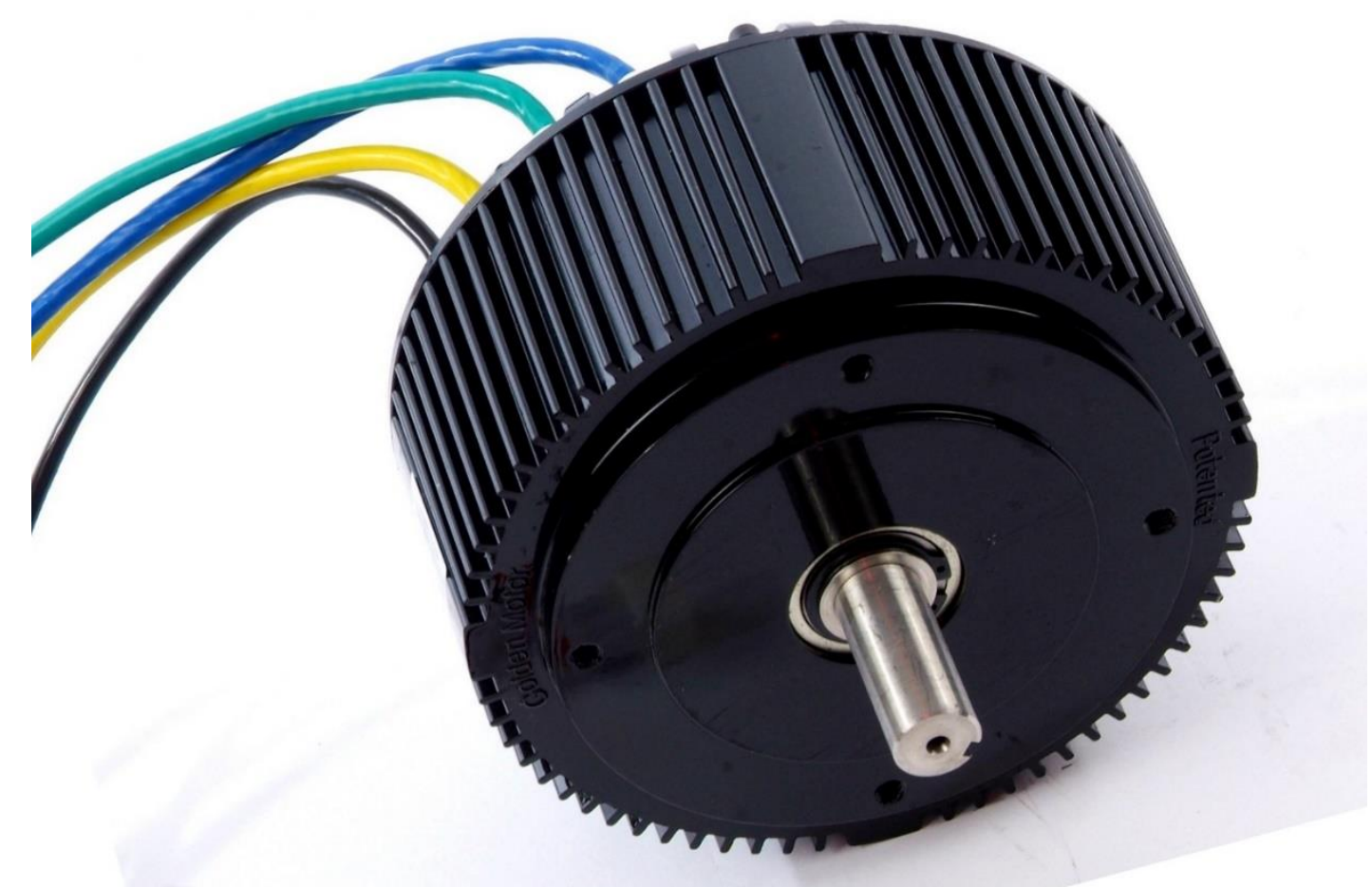

Figure 3. BLDC $72 \mathrm{~V} / 10 \mathrm{~kW}$ engine.

\section{FOC controller}

The FOC adopted in Class A conversion, shown in Figure 4, was specially designed for high-power BLDC engines, from $1 \mathrm{KW}$ to $20 \mathrm{KW}$, with voltage between $48 \mathrm{~V}$ and 96 $\mathrm{V}$. It uses an algorithm to control the magnetic field in vector space (VS), pulse width modulation (PWM), and a 32-bit microprocessor that incorporates the latest Advanced RISC Machine (ARM) core. The FOC system also controls torque and speed at the same time, in real time. Additional requirements for the operation are the performance with maximum torque control, constant power control, closed-circuit speed control, in place adjustment of parameters (via software and PC), self-control function system (poweron), regenerative braking, cruise speed model, and LED and sound to indicate operation and presence of irregularities. 


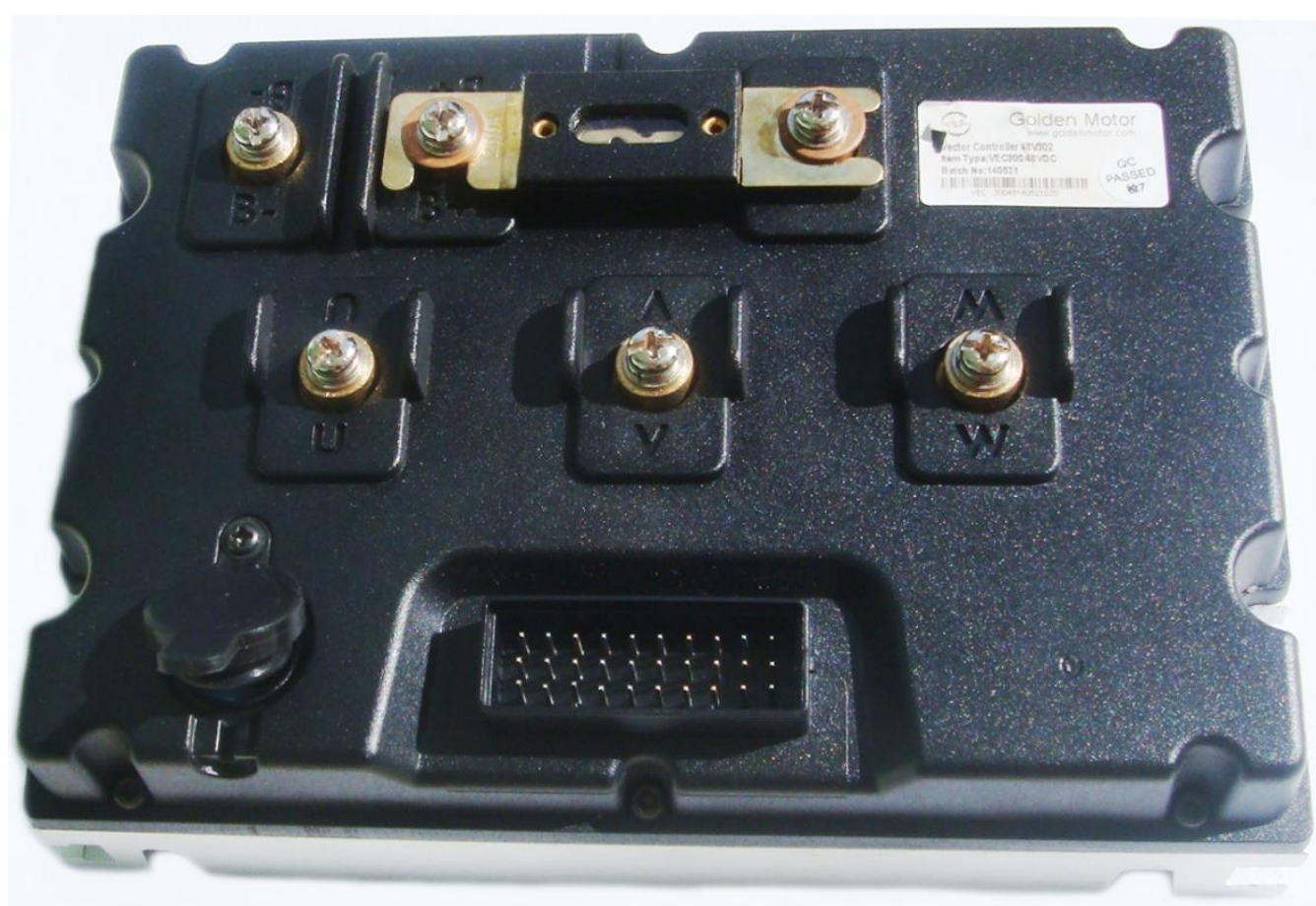

Figure 4. VE C500-72 V controller.

\section{Energy accumulator (battery)}

Electricity storage technology had its origins in the XVIII century with the first condenser, the Leiden jar (1745), and the Volta pile (1800). However, the proliferation of autonomous EVs was only enabled in 1859, with the invention of rechargeable lead-acid batteries by Gaston Planté, and its subsequent improvement by Camille Alphonse Faure in 1881 [1]. According to [4], the rechargeable lead-acid batteries present the lowest Watt hour (Wh) cost. Conversely, the Li-ion (Lithium-ion) batteries, thanks to their high energy densities, between 80 and $150 \mathrm{Wh} / \mathrm{kg}$, have been used in electric vehicles (EVs). The main characteristics of batteries and super capacitors, which are crucial for EVs, are the power capacity (measured in kW), and the stored energy (measured in kWh). Both depend on variables such as the charge depleting (CD) mode range, the type of operation in CD mode (pure or mixed electric), the steering cycle, vehicle design, and type of recharging, among others [4]. Power is defined as the energy transfer rate. In conventional cars, power is proportional to the rate at which gasoline is supplied to the internal combustion engine (ICE). The more a car accelerates, the more gasoline is consumed [4]. In the case of EVs, the increase in acceleration increases the withdrawal of energy from the battery, which is then delivered to the EV, increasing its rotation [2]. The battery power is a critical factor for EVs, whose performance is limited by the number of $\mathrm{kW}$ the battery is capable to supply [5]. The storage capacity, generally measured in $\mathrm{kWh}$, is the characteristic determining the distance that can be traveled in CD mode as well as the weight of the battery system, and is related to the amount of energy the battery is capable to store. It is important to highlight that there is a difference between the available energy and the total energy stored in a battery, as illustrated in Figure 5. 


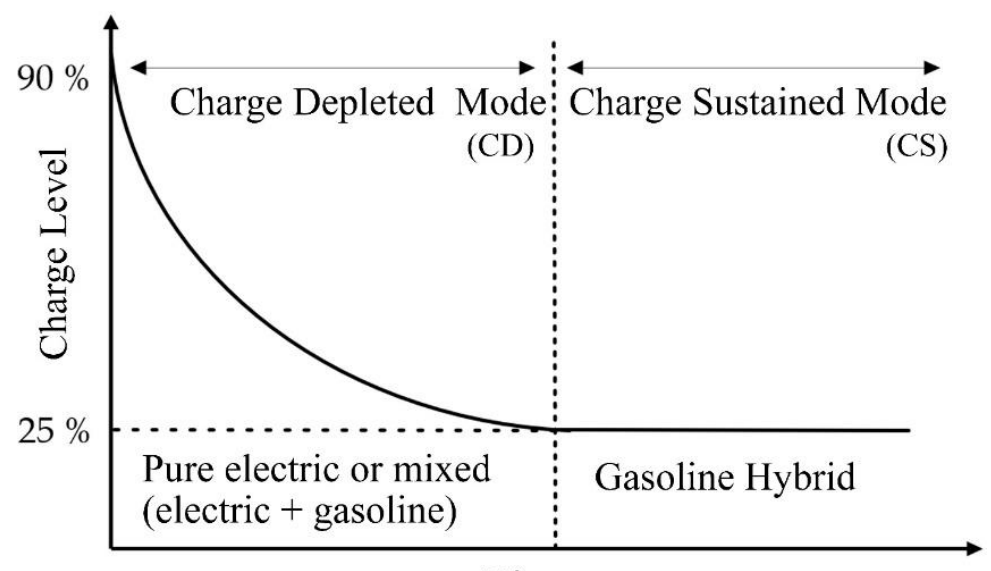

Figure 5. Typical Discharge Cycles.

Distance

Source: Electrification Coalition, 2009 [6].

Figure 5 shows that only part of the total energy is available, i.e. a fully charged battery may actually be below $100 \%$ of the total charge level, and will be considered discharged even if its charge is above $0 \%$. As an example, a battery with $10 \mathrm{kWh}$ of total capacity would only have $6.5 \mathrm{kWh}$ of available energy. Moreover, this amount would degrade with use, the latter being quantified by the numbers of deep cycles (starting at $90 \%$ charge level and ending at $25 \%$ ) and shallow cycles (the number of times the battery charge state varies). It is important to stress that degradation in shallow cycles is smaller than in deep cycles, and the temperature at which the battery is subjected when it is out of operation influences its longevity [4]. There are different battery technologies, and it is common to use measurement terms such as power density (or power per kilogram of battery $-\mathrm{W} / \mathrm{kg}$ ) and energy density (or energy per $\mathrm{kg}$ of battery - Wh/kg). Figure 6 compares the energy and power densities of different types of battery technologies [7]. In the Class A conversion, we used a $10.8 \mathrm{kWh}$ lead-acid bank of batteries, shown in Figure 7.

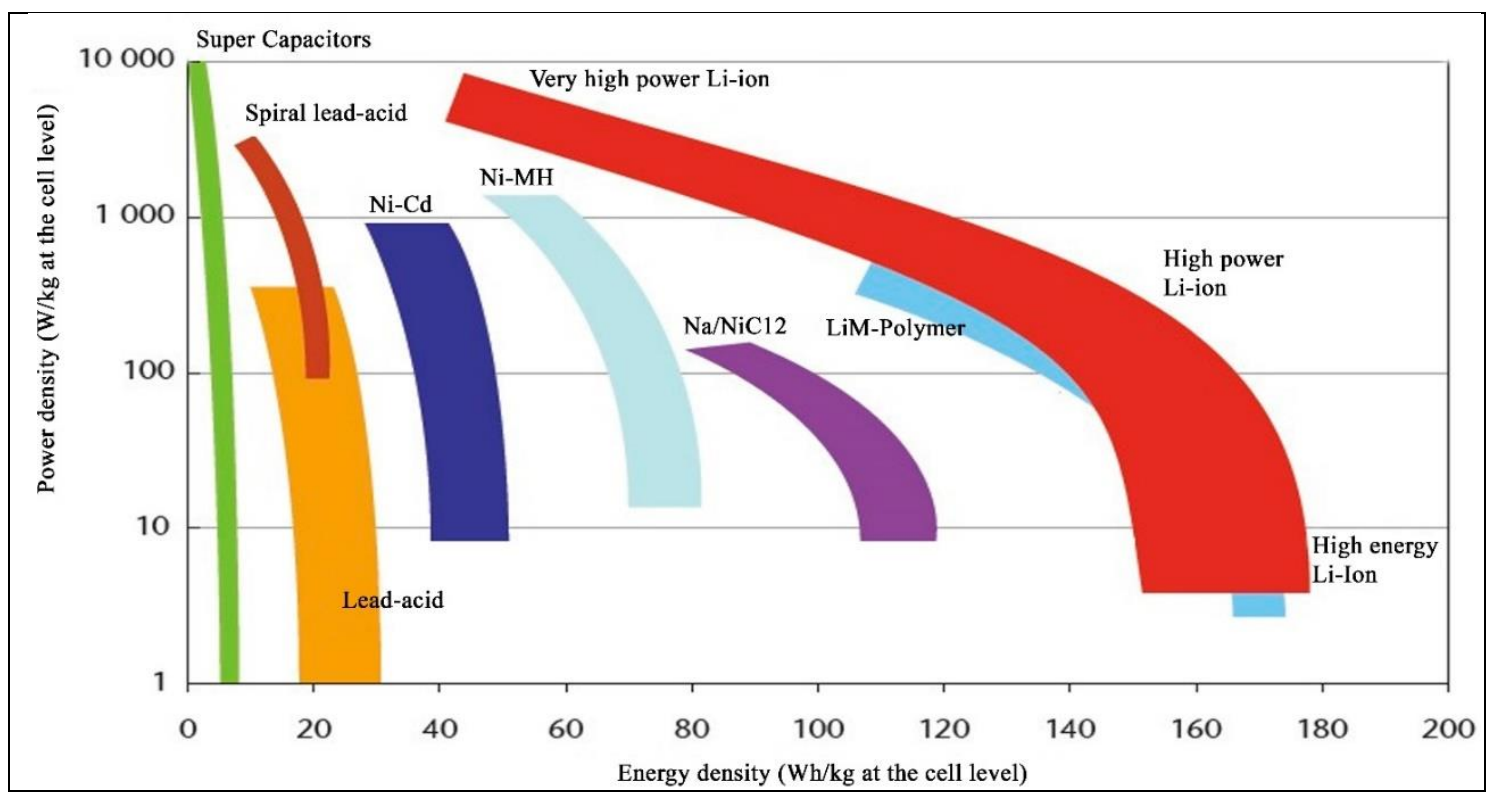

Figure 6. Energy Density and Power Density for different battery types.

Source: IEA (International Energy Agency), 2009 [7]. 


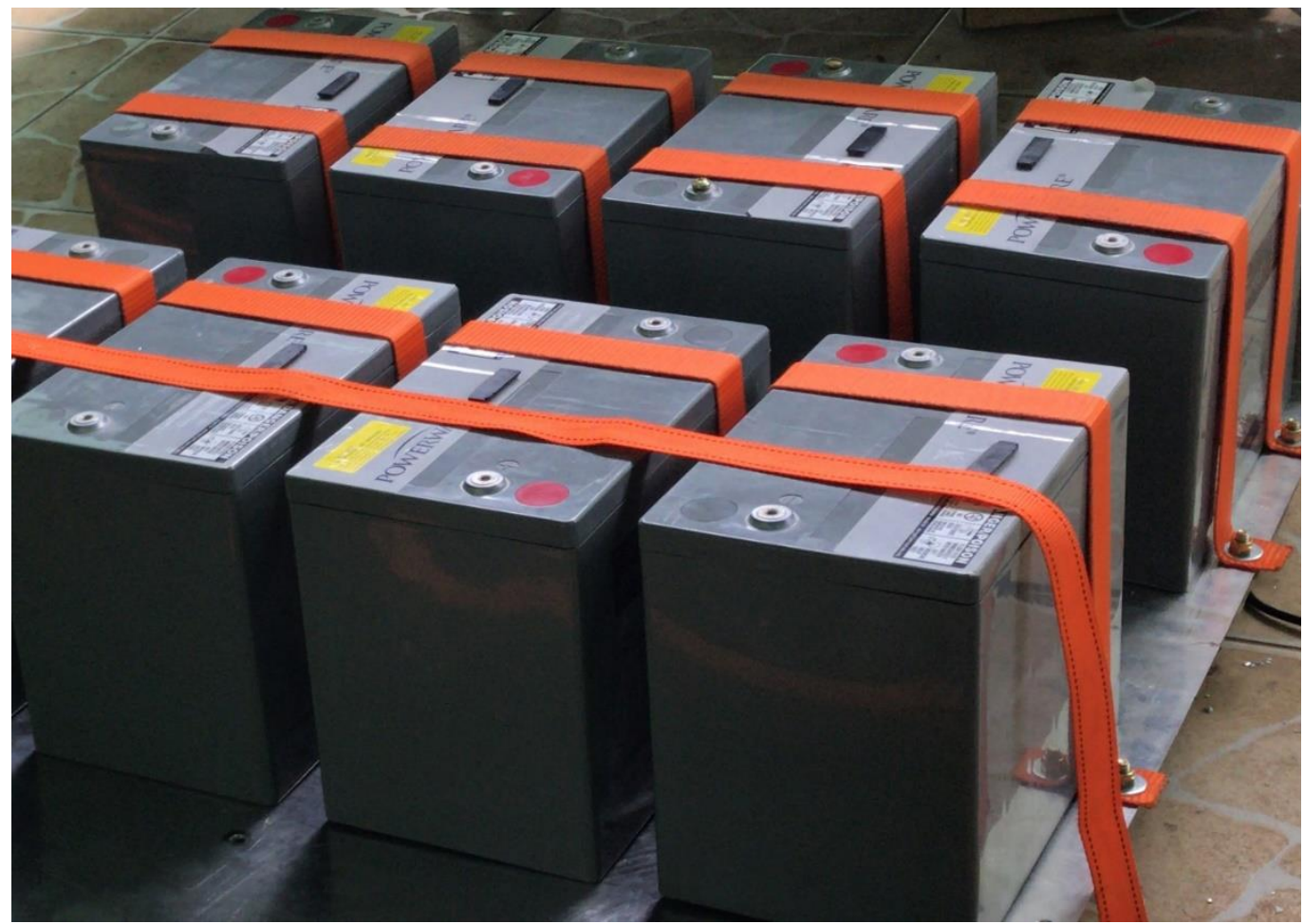

Figure 7. $10.8 \mathrm{kWh}$ battery bank.

\section{Variable transmission ratio}

The original variable transmission ratio (gearbox) of the vehicle was used, with some modifications. Figure 8 shows the engine after being coupled to the gearbox.

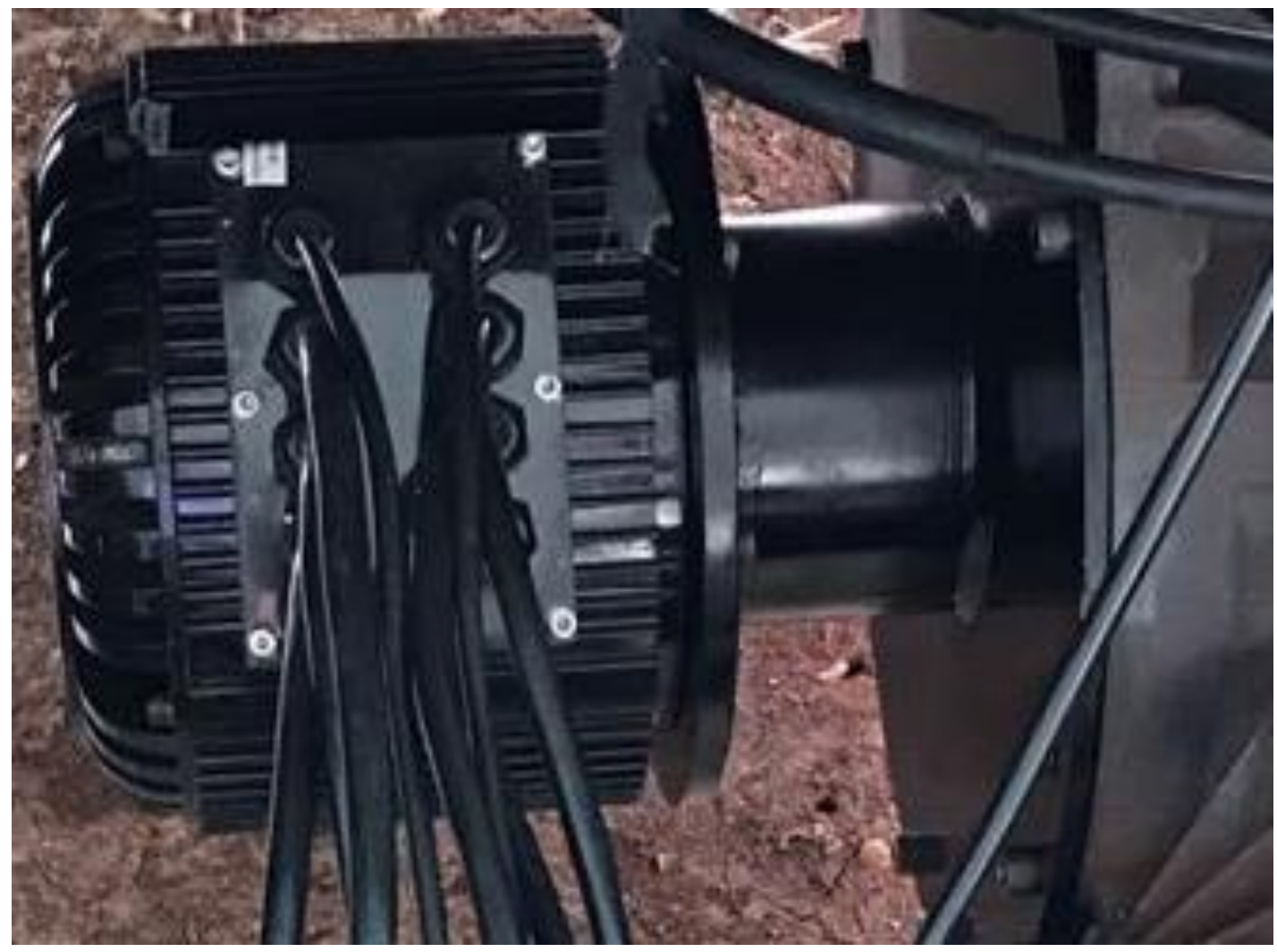

Figure 8. Engine already coupled to the gearbox. 


\section{Construction of control and measurement panels}

Table 2 shows the symbols adopted for the respective functions.

Table 2. Adopted symbols.

Function

Electric Steer
Cruise Speed
Regenerative Braking
Reverse gear (reverse motor rotation)

Source: Elaborated by the authors, 2018.

\section{Completed Command Panel}

Figure 9 shows the command panel ready and in operation.

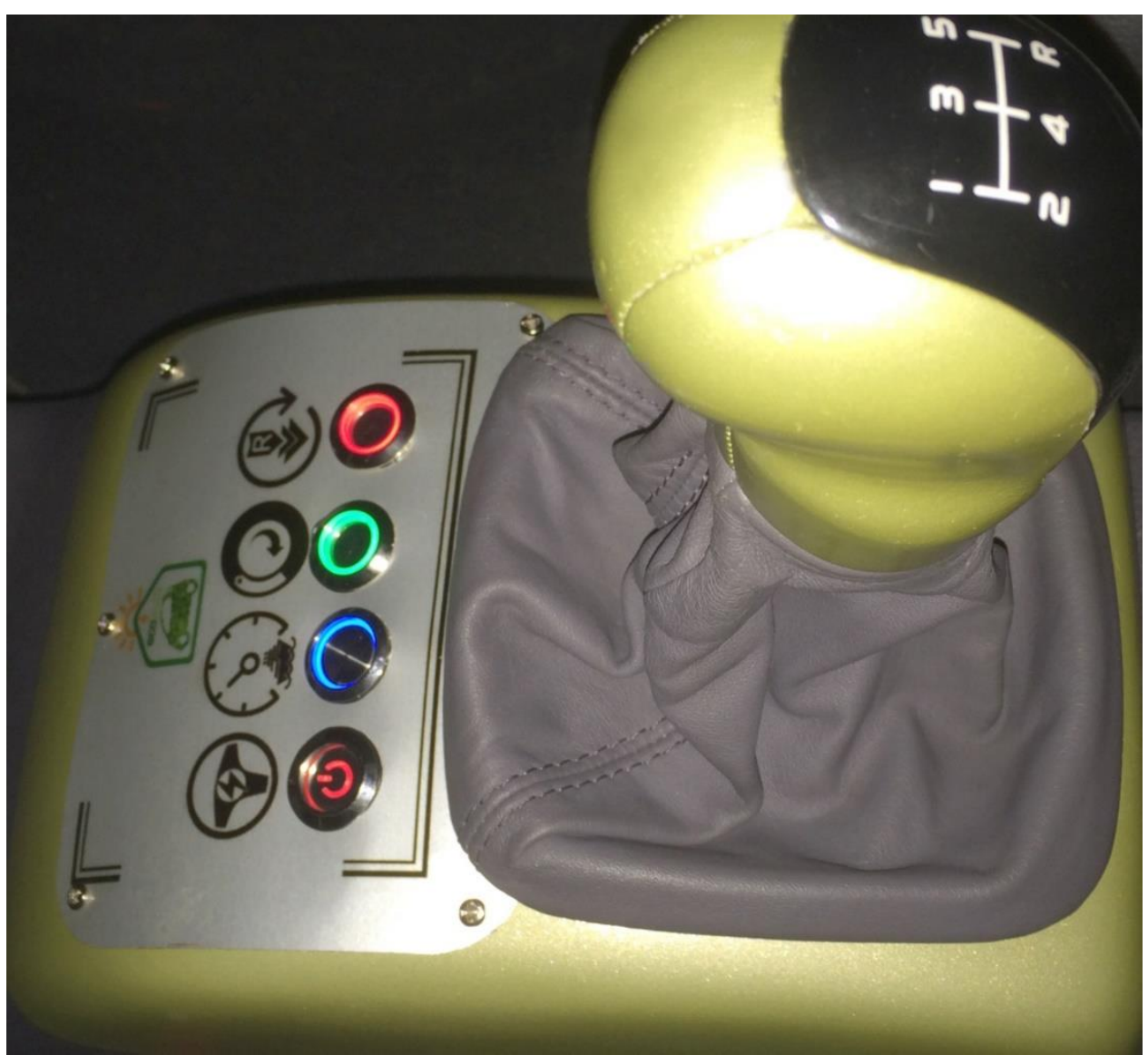

Figure 9. Command panel.

\section{Completed Measuring Panel}

Figure 10 shows the measuring panel ready and in operation. 


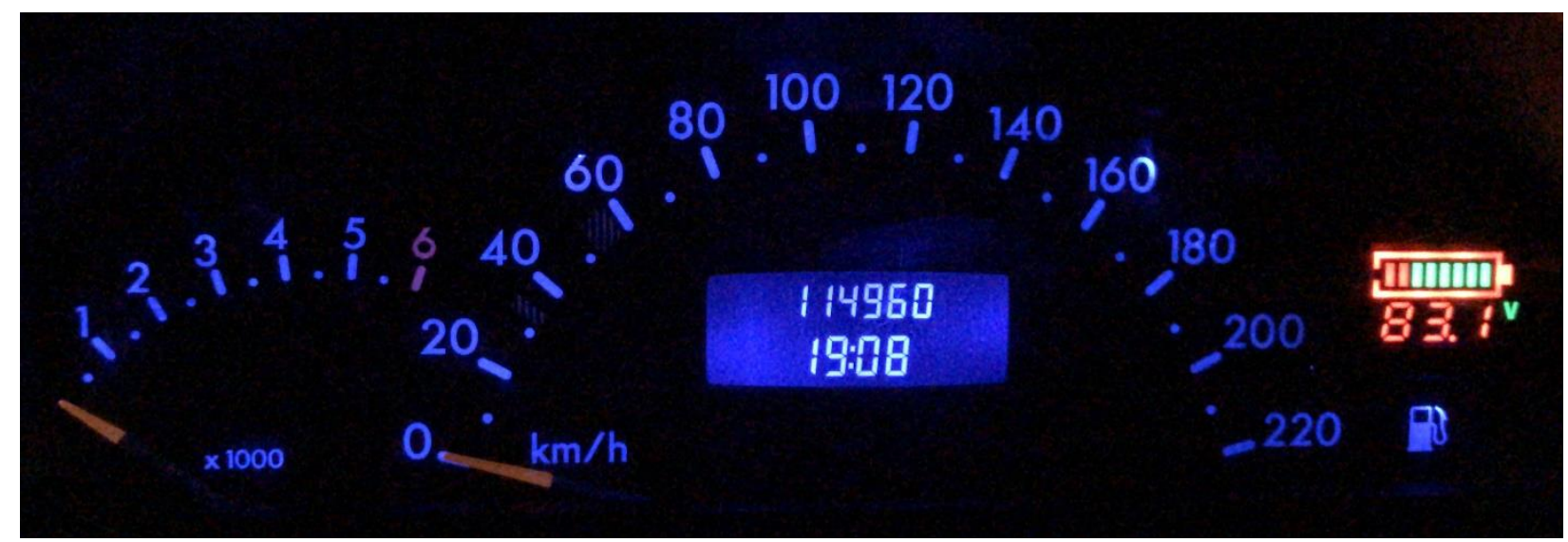

Figure 10. Measuring Panel.

\section{Completion of the eco auto}

Figure 11 presents a view of the interior of the Mercedes Benz Class A 190 car (Eco Auto) after being converted into a $100 \%$ EV. Figure 12 presents a view of the exterior of the car.

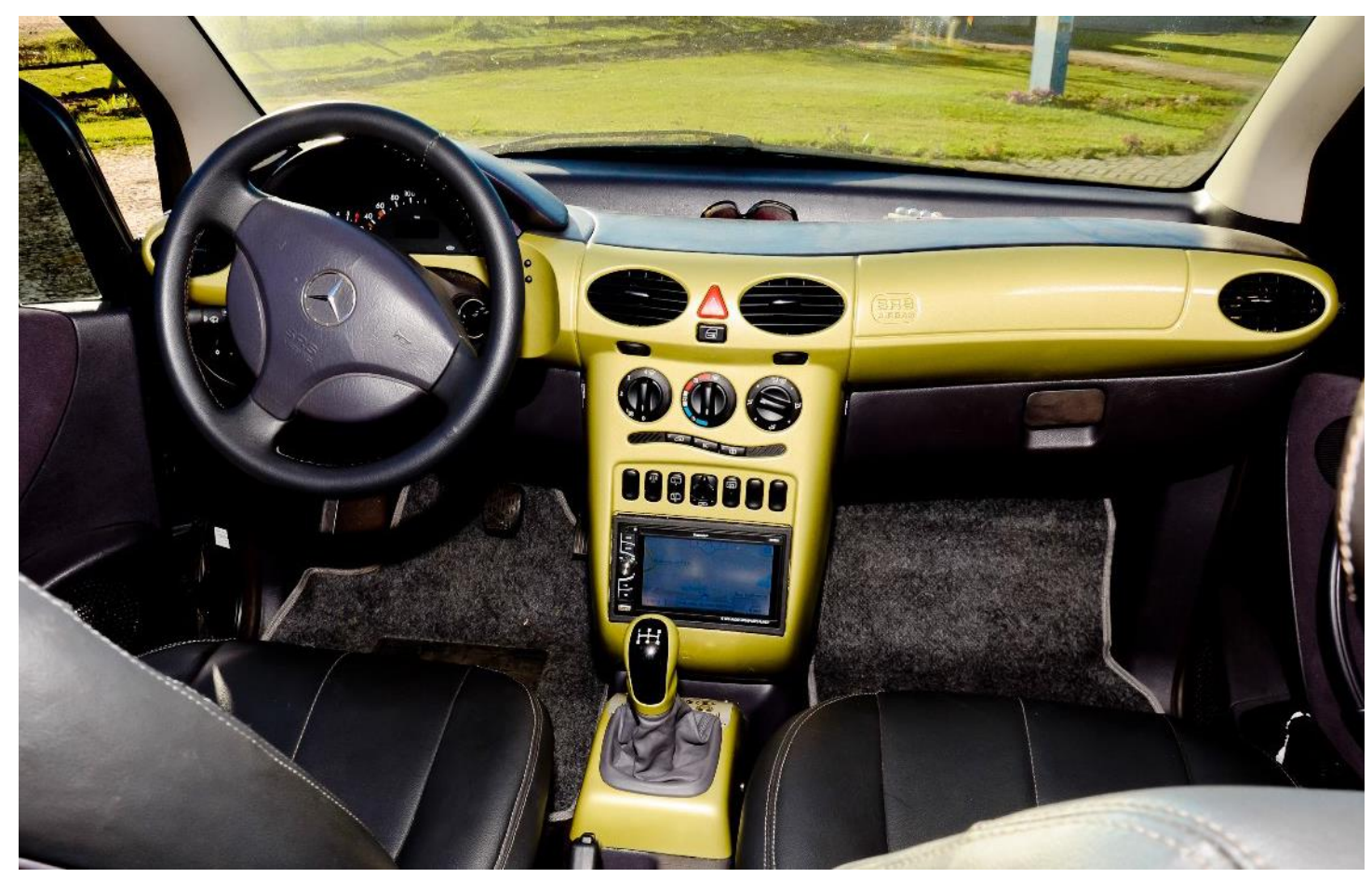

Figure 11. Interior of the Eco Auto. 


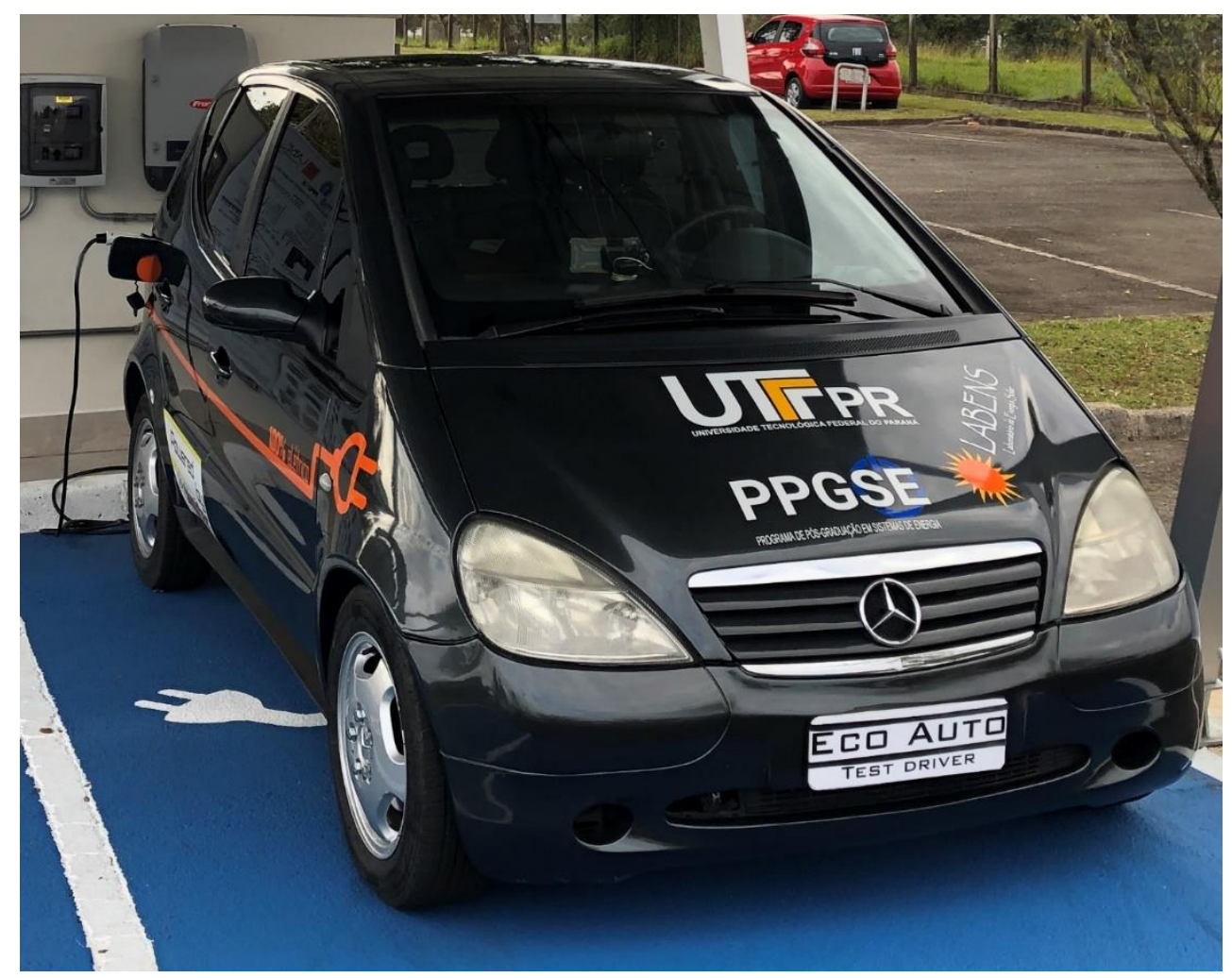

Figure 12. Exterior of the Eco Auto.

\section{RESULTS AND DISCUSSION}

The manufacturers are quick in promoting the economic virtues of the electric vehicles. They highlight the low price of recharge, which sometimes is even free at public terminals (city halls, shopping malls, etc., in some countries). The main downside of EVs, in the current state of technology, is the autonomy [8]. In this article, the values obtained from the tests conducted on the Eco Auto are presented. Table 3 shows the values obtained from tests carried out in downtown São Mateus do Sul-Paraná State, and on motorways, with the purpose of building a comparison basis and simulating the driving in different scenarios, such as in urban areas or motorways.

Table 3. Autonomy of the Eco Auto.

\begin{tabular}{cccc}
$\begin{array}{c}\text { Energy } \\
\text { consumption } \\
\text { Wh/km }\end{array}$ & $\begin{array}{c}\text { Price per } \\
\text { travelled km } \\
\text { B1 subgroup }\end{array}$ & Autonomy & Fare \\
\hline 307.4 & $\mathrm{R} \$ 0.1937$ & 35.1 & Copel B1 \\
206.2 & $\mathrm{R} \$ 0.1299$ & 52.3 & 0.6306 \\
256.8 & $\mathrm{R} \$ 0.1618$ & 43.7 & \\
\hline
\end{tabular}

\section{Price of a full recharge}

The price charged by Copel (Companhia Paranaense de Energia - the Energy Company of the State of Paraná) was used for the calculations. In particular, the conventional fare, subgroup B1, corresponding to a monthly consumption between 101 $\mathrm{kW}$ and $220 \mathrm{kWh}$, was considered. The cost is expressed in $\mathrm{R} \$ / \mathrm{kWh}$, as described in Table 4. 
Table 4. Conventional fare - subgroup B1.

$\begin{array}{llc}\mathrm{R} \$ / \mathrm{kWh} \text { B1-residential } & \text { ANEEL Resolution No. } & \text { With taxes: } \\ \text { Conventional fare } & 2,402 \text { of June 19, 2018 } & \text { ICMS and } \\ & \text { PIS/COFINS }\end{array}$

Monthly consumption less than or equal to $30 \mathrm{kWh}$ (free from ICMS)

$R \$ 0.16188$

$R \$ 0.17039$

Monthly consumption between $31 \mathrm{kWh}$ and $100 \mathrm{kWh}$

$R \$ 0.27750$

$R \$ 0.42045$

Monthly consumption between $101 \mathrm{kWh}$ and $220 \mathrm{kWh}$

$R \$ 0.41625$

$R \$ 0.63068$

Monthly consumption above $220 \mathrm{kWh}$

$R \$ 0.46250$

$\mathrm{R} \$ 0.70076$

Source: Elaborated by the authors, based on reference [9].

\section{CONCLUSION}

It is unquestionable that the electric vehicle $(E V)$ is increasingly becoming a solution to the issue of the high prices of fuels used in internal combustion engine (MCl) vehicles and the related pollution problems. However, one important downside of EVs is their high acquisition cost, which makes the investment impossible. On the other hand, the conversion of internal combustion engine $(\mathrm{MCl})$ vehicles into $\mathrm{EVs}$ has proved to be a viable alternative. This viability derives from the low average cost, i.e. $0.16 \mathrm{R} \$ / \mathrm{km}$ in average, considering an energy price of $0.63 \mathrm{R} \$ / \mathrm{kWh}$, which can reach zero if solar radiation is used to generate electricity through photovoltaic panels. Furthermore, EVs are an environmentally sustainable solution.

\section{REFERENCES}

1. Martins, J.; Brito, F. Carros Elétricos: Publindústria edições técnicas Itda, Portugal, 2011, p. 9-13.

2. CPqD - Centro de Pesquisa e Desenvolvimento. Mobilidade elétrica: caminho para um planeta sustentável, 2015, Available in: http://www.cpqd.com.br/midiaeventos/conexaocpqd/conexao-cpqd-janeiro-2015. [Accessed on: 2017 feb. 12].

3. Stephen, M. N. School of Electrical \& Electronic Engineering: Newcastle University, 2013. Available in: https://theses.ncl.ac.uk/dspace/bitstream/10443/2439/1/Naylor,\%20S\%2014.pdf. [Accessed on: 10 fev. 2017].

4. Baran R. A introdução de veículos elétricos no Brasil: Avaliação do Impacto no consumo de gasolina e eletricidade, 2012. Tese de Doutorado. Universidade Federal do Rio de Janeiro. [Internet]. Available in: http://www.ppe.ufrj.br/ppe/production/tesis/baran.pdf . [Accessed on: 2017 jul 07].

5. Pinho, T.; Galdino, M. A. Manual de Engenharia para Sistemas Fotovoltaicos. Rio de Janeiro: CEPEL - CRESESB, 2014. 179-203 p.

6. Electrification Coalition. Electrification Roadmap: Revolutionizing Transportation and Achieving Energy Security. Electrification Coalition, Washington, DC. 2009.

7. IEA. Technology Roadmap. Electric and plug-in hybrid electric vehicles: International Energy Agency, Paris, France, 2009.

8. Silva JE, Tonin F, Urbanetz JJ. Veículos elétricos e a geração distribuída partir de sistemas fotovoltaicos: Conferência internacional de energias inteligentes. Curitiba, 2016. 
9. Copel. Tarifa Convencional: subgrupo B1. Available in: http://www.copel.com/hpcopel/root/nivel2.jsp?endereco=\%2Fhpcopel\%2Froot\%2Fpagcope I2.nsf\%2F5d546c6fdeabc9a1032571000064b22e\%2Fc28b22b01ad918240325748800593 9bb, 2018.

(C) $(1) \otimes$

(C) 2018 by the authors. Submitted for possible open access publication under the terms and conditions of the Creative Commons Attribution (CC BY NC) license (https://creativecommons.org/licenses/by-nc/4.0/). 